\title{
Fluxo de seiva e fotossíntese em laranjeira 'Natal' com clorose variegada dos citros
}

\author{
Eduardo Caruso Machado(1), Ricardo Ferraz de Oliveira(2), Rafael Vasconcelos Ribeiro(1), Camilo Lázaro Medina(3), \\ Eduardo Sanches Stuchi(4), Fábio Ricardo Marin ${ }^{(5)}$, José Aliçandro Bezerra da Silva ${ }^{(6)}$ \\ e Simone Rodrigues da Silva ${ }^{(7)}$
}

\begin{abstract}
(1)Instituto Agronômico, Centro de Pesquisa e Desenvolvimento em Ecofisiologia e Biofísica, Caixa Postal 28, CEP 13001-970 Campinas, SP. E-mail: caruso@iac.sp.gov.br, rafael@iac.sp.gov.br (2)Escola Superior de Agricultura Luiz de Queiroz, Dep. de Ciências Biológicas, Caixa Postal 9, CEP 13418-900 Piracicaba, SP. E-mail: rfolivei@esalq.usp.br (3)Grupo de Consultores em Citros, Caixa Postal 39, CEP 13490-070 Cordeirópolis, SP. E-mail: clmedina@mpc.com.br (4)Embrapa Mandioca e Fruticultura Tropical, Caixa Postal 7, CEP 48380-000 Cruz das Almas, BA. E-mail: stuchi@estacaoexperimental.com.br ${ }^{(5)}$ Embrapa Informática Agropecuária, Caixa Postal 6041, CEP 13083-886 Campinas, SP. E-mail: marin@cnptia.embrapa.br (6)Universidade Federal do Vale do São Francisco, Caixa Postal 252, CEP 56304-410 Petrolina, PE. E-mail: jalissandro@bol.com.br (7)Estação Experimental de Citricultura de Bebedouro, Caixa Postal 74, CEP 14700-971 Bebedouro, SP.

E-mail: simone@estacaoexperimental.com.br
\end{abstract}

Resumo - O objetivo deste trabalho foi avaliar os efeitos da clorose variegada dos citros (CVC), no fluxo de seiva, trocas gasosas e atividade fotoquímica em laranjeira 'Natal', com e sem CVC, em condição de campo. O curso diário do fluxo de seiva, potencial da água na folha, assimilação de $\mathrm{CO}_{2}$, transpiração, condutância estomática e eficiência quântica máxima e efetiva do fotossistema II foram avaliados. O delineamento experimental foi em blocos ao acaso com cinco repetições. O fluxo de seiva foi 1,9 vez superior nas plantas sadias em relação às doentes. Em plantas doentes ocorreu queda de 43, 28 e 33\% na assimilação de $\mathrm{CO}_{2}$, condutância estomática e transpiração, respectivamente. As plantas com CVC apresentaram fotoinibição dinâmica. Uma vez que a eficiência quântica efetiva apresentou um padrão de resposta semelhante, durante o dia, em ambos os tratamentos, o efeito protetor da fotorrespiração no aparato fotoquímico em plantas com CVC é discutido. As quedas de assimilação de $\mathrm{CO}_{2}$, transpiração e de fluxo de seiva, nas plantas com $\mathrm{CVC}$, foram decorrentes do menor valor da condutância estomática, possivelmente causado pela colonização dos vasos do xilema pela Xylella fastidiosa.

Termos para indexação: Citrus sinensis, Xylella fastidiosa, assimilação de $\mathrm{CO}_{2}$, condutância estomática, fluorescência da clorofila, transpiração.

\section{Sap flow and photosynthesis of 'Natal' sweet orange plants with citrus variegated chlorosis}

\begin{abstract}
The objective of this work was to evaluate the effects of citrus variegated chlorosis (CVC) on sap flow, gas exchanges and photochemical activity in 'Natal' sweet orange plants with and without CVC under field condition. Diurnal courses of sap flow, leaf water potential, $\mathrm{CO}_{2}$ assimilation rate and transpiration, stomatal conductance, potential and effective quantum efficiency of photosystem II were evaluated. The experiment was arranged in a random block design with five repetitions. Healthy plants showed sap flow values around 1.9 times higher than injured ones. Injured plants exhibited reductions of 43, 28 and $33 \%$ in $\mathrm{CO}_{2}$ assimilation rate, stomatal conductance and leaf transpiration, respectively. CVC-affected plants showed dynamic photoinhibition. Since healthy and injured plants showed similar diurnal course of effective quantum efficiency, the possible influence of photorespiration on photochemical apparatus in CVC-affected plants is discussed. Reductions in $\mathrm{CO}_{2}$ assimilation rate, transpiration and sap flow of injured plants were induced by low stomatal conductance values, which was probably due to the xylem vessel colonization by Xylella fastidiosa.

Index terms: Citrus sinensis, Xylella fastidiosa, $\mathrm{CO}_{2}$ assimilation, stomatal conductance, chlorophyll fluorescence, transpiration.
\end{abstract}

\section{Introdução}

A clorose variegada dos citros (CVC) é uma das principais doenças que afeta laranjeiras doces no Brasil.
O agente causal desta doença é a bactéria Xylella fastidiosa, que coloniza exclusivamente o xilema das plantas, causando obstruções (Purcell \& Hopkins, 1996). Alves et al. (2004) observaram, em laranjeiras com 
sintomas leves de CVC, obstrução de cerca de 8\% dos vasos xilemáticos do pecíolo das folhas, enquanto as plantas com sintomas severos de CVC apresentaram 11,8\% de vasos obstruídos.

As bactérias no xilema agregam-se e prendem-se às paredes dos vasos condutores por meio de polissacarídeos extracelulares produzidos e excretados pelas próprias bactérias. Assim, os sintomas de deficiência hídrica, em plantas afetadas pela $X$. fastidiosa, provavelmente são ocasionados pela colonização e obstrução do fluxo de seiva pelo xilema, promovido pelas próprias bactérias e/ou pela deposição de gomas e tiloses.

Diminuição da condutância estomática, das taxas de fotossíntese e de transpiração e do potencial da água na folha, em plantas com CVC, são atribuídas à obstrução dos vasos do xilema (Machado et al., 1994; Habermann et al., 2003a, 2003b; McElrone et al., 2003; Ribeiro et al., 2003a, 2003b, 2004). A queda na taxa de fotossíntese afeta o crescimento, visto que praticamente todo o carbono acumulado na planta é proveniente desse processo. A luz absorvida pelas moléculas de clorofila é utilizada nas reações fotoquímicas, dando prosseguimento à fotossíntese, podendo o excesso de energia ser dissipado como calor, ou reemitido como luz, num comprimento de onda maior, isto é, fluorescência da clorofila. Estes três processos são competitivos, de modo que o aumento da eficiência de um acarreta a diminuição dos outros.

As medidas de fluorescência da clorofila fornecem informações sobre a variação da eficiência fotoquímica e da dissipação de calor nos fotossistemas (Baker \& Rosenqvist, 2004). Em plantas infectadas com CVC com redução da taxa de assimilação de $\mathrm{CO}_{2}$, observou-se que a fotorrespiração funciona como um mecanismo fotoprotetor, que atenua o excesso de excitação sobre o fotossistema II (Habermann et al., 2003a; Ribeiro et al., 2003a, 2004).

O objetivo deste trabalho foi avaliar os efeitos da CVC no fluxo de seiva, trocas gasosas e atividade fotoquímica de laranjeiras 'Natal’ em condição de campo.

\section{Material e Métodos}

O experimento foi instalado em pomar plantado em fevereiro de 1999, com laranjeiras 'Natal' (Citrus sinensis L. Osb.), enxertadas em limoeiro ‘Cravo’ (Citrus limonia L. Osb.), na Estação Experimental de Citricultura de Bebedouro, no Município de Bebedouro, SP (2057'S, $48^{\circ} 29^{\prime} \mathrm{O}$, altitude de $529 \mathrm{~m}$ ), em área com Latossolo
Vermelho-Escuro, fase arenosa. O espaçamento de plantio foi de $6 \mathrm{~m}$ entre linhas e $4 \mathrm{~m}$ entre plantas.

O delineamento estatístico foi em blocos ao acaso com cinco repetições. Cada parcela constou de 24 plantas distribuídas em três linhas de oito plantas cada. A linha central de cada parcela foi reservada para as amostragens necessárias. Duas linhas laterais de plantas e uma planta em cada extremidade da linha central constituíram a bordadura da parcela. A área útil de cada parcela foi de $96 \mathrm{~m}^{2}$ (seis plantas), e a de bordadura foi de $480 \mathrm{~m}^{2}$. Plantas sadias e plantas com CVC constituíram os tratamentos. Os resultados foram analisados pelo teste $\mathrm{F}$ e as médias comparadas pelo teste de Tukey a 5\% de probabilidade.

Foram realizadas aplicações de produtos sistêmicos (via solo - aldicarb - e via tronco - imidacloprid), visando a impedir a permanência de cigarrinhas e evitar a disseminação da $X$. fastidiosa de forma descontrolada. Dez meses depois do plantio, metade das laranjeiras foi submetida à inoculação de $X$. fastidiosa, utilizando-se enxertia por encostia, com mudas inoculantes acondicionadas em tubetes de $120 \mathrm{~mL}$, em que, sobre o porta enxerto 'Cravo', foi enxertado ramo de laranjeira 'Pêra' contaminado, conforme Nunes et al. (2004). Plantas adultas, com inoculação e sem inoculação, foram submetidas à análise para detecção da $X$. fastidiosa por meio do teste de PCR (Pooler \& Hartung, 1995).

As plantas foram irrigadas utilizando-se um microaspersor autocompensado por planta, com vazão de $42 \mathrm{~L} \mathrm{~h}^{-1}$, com ângulo de molhamento de $300^{\circ}$. A irrigação foi realizada duas vezes por semana, e o volume de água fornecido por planta resultou do balanço entre a lâmina d'água correspondente ao total de chuva no intervalo entre as duas irrigações e a lâmina d'água relativa à evapotranspiração total da cultura. Os dados de temperatura de bulbo seco e úmido foram medidos diariamente por meio de uma estação meteorológica automática localizada a $0,5 \mathrm{~km}$ do pomar.

O fluxo de seiva foi medido entre os dias 2 e 12 de maio de 2001, pela técnica do balanço de calor caulinar (Sakuratani, 1981), utilizando-se sensores SGB19 e SGB25 (Dynamax Inc.) fixados aos caules das árvores. A técnica é fundamentada na aplicação de uma quantidade constante e conhecida de calor a um segmento de caule. De 24 a 48 horas, dependendo das características do caule, uma condição de equilíbrio dinâmico é atingida. Sob essa condição, o fluxo de calor fornecido e o fluxo no caule são balanceados. Detalhes da técnica em citros são apresentados por Trejo-Chandia et al. (1997). 
O fluxo de seiva foi medido em dez laranjeiras 'Natal', cinco sadias e cinco com CVC. Os sensores foram instalados nos troncos, 60 a $90 \mathrm{~cm}$ acima da superfície do solo. Antes da instalação dos sensores, aplicou-se uma pasta com alta condutividade elétrica (Dow Corning 4, Dow Corning Corporation) para otimizar o contato entre a fonte de calor e termopares com o caule. Depois da instalação, os sensores foram envolvidos com cinco a seis camadas de papel-alumínio, a fim de reduzir o efeito da radiação incidente. A condutância térmica individual de cada sensor foi estimada durante as medidas noturnas, entre 22 e $5 \mathrm{~h}$, período em que o fluxo foi considerado nulo. $\mathrm{O}$ valor médio observado às $4 \mathrm{~h}$ foi utilizado nos cálculos dos fluxos. Foi utilizado o valor de $0,54 \mathrm{~W} \mathrm{~m}^{-1} \mathrm{~K}^{-1}$ para o caule da laranjeira, e adotou-se o valor de $0,42 \mathrm{~W} \mathrm{~m}^{-1}{ }^{\circ} \mathrm{C}^{-1}$ como condutividade térmica para o tronco de laranjeira, conforme Steinberg et al. (1989).

Durante as medidas, o sinal dos sensores foi coletado por um sistema automático de coleta de dados (CR7X, Campbell Sci.), programado para processar os sinais a cada segundo e calcular e armazenar os valores integrados de fluxo a cada intervalo de 60 minutos. Foi utilizado um regulador de voltagem portátil (PS3002D, Dawer) para alimentação elétrica da fonte de calor. Depois do período de medidas de fluxo de seiva, a área foliar de todas as folhas, referentes ao ramo em que o sensor estava instalado, foi determinada por um medidor automático de área foliar (Li-3100, Li-Cor. Inc.). A área foliar total dos ramos foi determinada pela soma da área de todas as folhas. O fluxo de seiva foi, então, expresso em $\mathrm{g} \mathrm{m}^{-2} \mathrm{~h}^{-1}$.

Em um único dia claro e com poucas nuvens, foram realizadas medidas das taxas de assimilação líquida de $\mathrm{CO}_{2}$ e de transpiração, da condutância estomática, da densidade de fluxo de fótons fotossinteticamente ativos (DFFFA) e da temperatura foliar, com um sistema portátil de medidas de fotossíntese (LI-6400, Li-Cor Inc.). Essas variáveis foram medidas sob condições naturais, entre 7 e 17h, em intervalos de aproximadamente uma hora. Utilizaram-se folhas completamente expandidas com idade ao redor de seis meses, expostas ao sol durante todo o período de medidas, segundo Machado et al. (1994). As medidas de trocas gasosas foram feitas com cinco repetições por tratamento. As trocas gasosas foram medidas em folhas pertencentes aos mesmos ramos em que foi medido o fluxo de seiva.
Medidas de fluorescência foram efetuadas concomitantemente com as de trocas gasosas, em plantas intactas, com a utilização de um fluorômetro modulado (PAM-2000, Walz). As medidas descritas foram feitas em cinco repetições, nas mesmas folhas ou em folhas vizinhas e semelhantes às utilizadas para medidas de trocas gasosas. As fluorescências máxima $\left(\mathrm{F}_{\mathrm{m}}\right)$ e mínima $\left(\mathrm{F}_{\mathrm{o}}\right)$ foram determinadas às $6 \mathrm{~h}$ em folhas adaptadas ao escuro, durante o período noturno e, em seguida, em intervalos de 1 hora, entre 7 e 17h, em folhas adaptadas ao escuro, por um período de 30 minutos. As fluorescências em estado de equilíbrio dinâmico (F) e máxima ( $\mathrm{F}_{\mathrm{m}}$ ') na presença de luz foram avaliadas em intervalos de uma hora, entre 7 e $17 \mathrm{~h}$. Foram calculadas as relações: eficiência quântica máxima $\left[\Phi_{\text {máxima }}=\left(\mathrm{F}_{\mathrm{m}}-\mathrm{F}_{\mathrm{o}}\right) / \mathrm{F}_{\mathrm{m}}\right]$ e efetiva $\left[\Phi_{\text {efetiva }}=\left(\mathrm{F}_{\mathrm{m}}{ }^{\prime}-\mathrm{F}\right) / \mathrm{F}_{\mathrm{m}}{ }^{\prime}\right]$ do fotossistema II, de acordo com Bilger et al. (1995).

O potencial da água na folha foi medido pelo método descrito por Kaufmann (1968), com uma câmara de pressão, às 6 e às 14h, com quatro repetições para cada tratamento. As folhas utilizadas localizavam-se próximas às das medidas de trocas gasosas e atividade fotoquímica.

\section{Resultados e Discussão}

As laranjeiras com inoculação de $X$. fastidiosa apresentaram teste de PCR positivo e sintomas leves de CVC (classe 1), na escala de Amorim et al. (1993). Nas plantas sem inoculação, não foram observados sintomas de CVC, nem a presença de $X$. fastidiosa pela PCR. Alves et al. (2004) observaram, em laranjeiras com sintomas leves de CVC, que ao redor de $8 \%$ dos vasos estavam obstruídos.

Nas primeiras horas da manhã, o fluxo de seiva foi relativamente baixo, aumentando gradativamente até um máximo entre 12 e 14h, diminuindo posteriormente até um valor mínimo no final da tarde (Figura 1). A variação diurna no fluxo de seiva em relação à média dos dez dias foi, possivelmente, ocasionada por pequenas variações de temperatura e deficit de pressão de vapor (DPV), ao longo do período de medida (Figura 1). A variação do fluxo de seiva acompanhou, aproximadamente, o padrão de variação do DPV e da radiação solar (Figuras 1 e 2). A dinâmica diurna do fluxo de seiva foi semelhante em plantas dos dois tratamentos, porém, significativamente menor nas plantas com CVC. A integração do fluxo de seiva durante o dia, em plantas 
sadias, foi cerca de 1,9 vez superior à das plantas com CVC, evidenciando o efeito da infecção da $X$. fastidiosa nos vasos do xilema.

Apesar de a umidade do solo ter sido mantida próxima da capacidade de campo em ambos os tratamentos, as folhas das plantas com CVC apresentaram sintomas de deficiência hídrica, principalmente nas horas de maior demanda atmosférica. Os valores do potencial da água na folha ( $\Psi$ ) nas plantas com CVC foram significativamente menores que os observados nas plantas sadias (Figura 3). Houve, portanto, relação entre sintomas de deficiência hídrica e quedas no fluxo de seiva e no $\Psi$ nas laranjeiras com CVC, em relação às sadias.

A Figura 2 mostra a variação diária da temperatura e do DPV, em intervalos de 30 minutos, e de DFFFA, em intervalos de uma hora, para o dia em que foram efetuadas as medidas de trocas gasosas e de fluorescência da clorofila. As respostas de assimilação de $\mathrm{CO}_{2}$, condutância estomática e transpiração (Figura 4), em laranjeiras sadias e com CVC, também apresentaram padrão de variação diurna semelhante. Isto é, apresentaram valores máximos ao redor das $9 \mathrm{~h}$ e, depois, decresceram paulatinamente, até atingir valores mínimos, no final do período de medidas, ao redor das $17 \mathrm{~h} 30$. Apesar de o padrão diurno ter sido semelhante, plantas com CVC tiveram valores estatisticamente $(p<0,05)$ menores que os observados nas plantas sadias. Em decorrência da menor taxa de transpiração e, conseqüentemente, de resfriamento, em laranjeiras com CVC, a temperatura da folha $\left(T_{C V C}\right)$ foi maior em relação à das plantas sadias $\left(\mathrm{T}_{\text {sadias }}\right)$, sendo tal relação dada pela equação $\mathrm{T}_{\mathrm{CVC}}=4,36+0,94 \mathrm{~T}_{\text {sadias }}(\mathrm{p}<0,001)$.

$\mathrm{O}$ aumento do fluxo de seiva durante o período matutino (Figura 1) parece estar relacionado à maior abertura estomática (Figura 4), ocasionada pelo aumento da temperatura e da radiação solar (Figura 2). Por sua vez, a manutenção do fluxo de seiva, no período da tarde, está possivelmente relacionada ao aumento de DPV que, mesmo causando fechamento parcial dos estômatos, mantém a taxa de transpiração elevada (Figura 4). A abertura estomática é dependente do estado hídrico da folha e da demanda evaporativa da atmosfera (Angelocci et al., 2004). Tanto nas plantas sadias quanto nas infectadas, os estômatos exerceram forte controle no fluxo transpiratório ao longo do dia (Figuras 1 e 4). A queda acentuada dos valores de $\Psi$ (Figura 3 ), ao longo do dia, indicou que a taxa de absorção de água não compensou a taxa de perda de água pela transpiração. Desta forma, com o aumento da demanda atmosférica, e principalmente nas horas de maior demanda, houve fechamento parcial dos estômatos, causando queda na taxa de transpiração de folhas expostas (Figura 4). No entanto, em ambos tratamentos, a redução da transpiração não impediu o decréscimo de $\Psi$ no decorrer do dia, o que pode estar relacionado à queda do conteúdo relativo de água na folha. Os menores valores de transpiração e fluxo de seiva das plantas com CVC
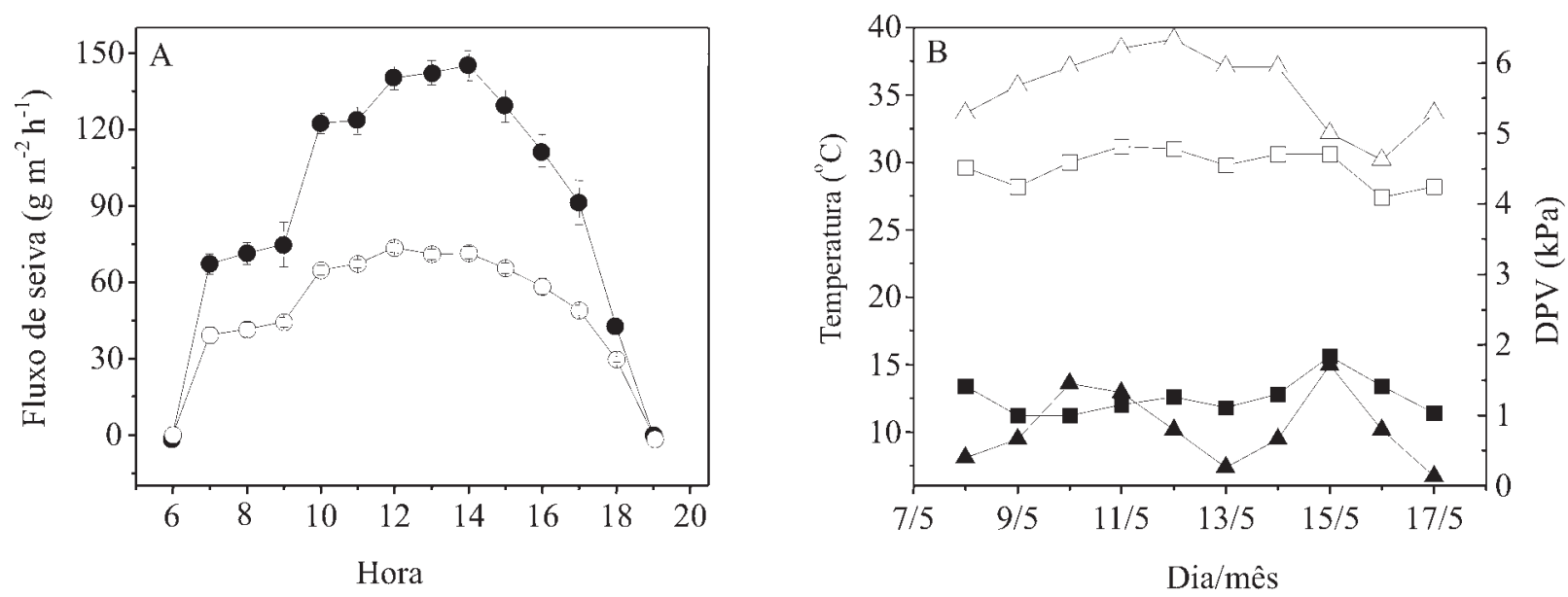

Figura 1. Fluxo médio de seiva em laranjeira 'Natal' com clorose variegada dos citros (O) e sadia (๑), entre 6 e 19h (A), temperatura máxima ( $\square$ ) e mínima ( $\square$ ) do ar e deficit de pressão de vapor (DPV) às 7 h $(\boldsymbol{\Delta})$ e $15 \mathrm{~h}(\triangle)$, no período de medida do fluxo de seiva, entre os dias 8 e 18 de maio de 2001 (B). Valores expressam a média de dez dias de medidas, com cinco repetições por dia, e as barras indicam os respectivos desvios-padrões da média. 
(Figuras 1 e 4) foram ocasionados pelos menores valores de condutância estomática nestas plantas em relação às sadias (Figura 4). O menor valor de condutância estomática das plantas com CVC possivelmente foi causado pela obstrução parcial do xilema por sua colonização pela $X$. fastidiosa, aumentando a resistência ao fluxo de água para as folhas (McElrone et al., 2003; Alves et al., 2004), causando fechamento parcial dos estômatos, mais acentuado nas plantas infectadas em relação às sadias.

Em geral, $\Psi$, medido antes do nascer do sol, indica o potencial da água no solo, uma vez que uma noite é suficiente para que o $\Psi$ e o potencial de água do solo entrem em equilíbrio (Nobel, 1999). No entanto, nas laranjeiras com CVC, o $\Psi$ não atingiu valores semelhantes aos das plantas sadias, sugerindo que a presença de bactérias no xilema afetou a recuperação total de $\Psi$, induzindo tal desequilíbrio em relação às plantas sadias. A não-reidratação durante a noite, nas plantas com CVC, causou redução do conteúdo de água e de $\Psi$ na folha no dia seguinte, provocando maior diminuição de condutância estomática, em relação às plantas sadias (Figura 4). Assim, a obstrução dos vasos do xilema

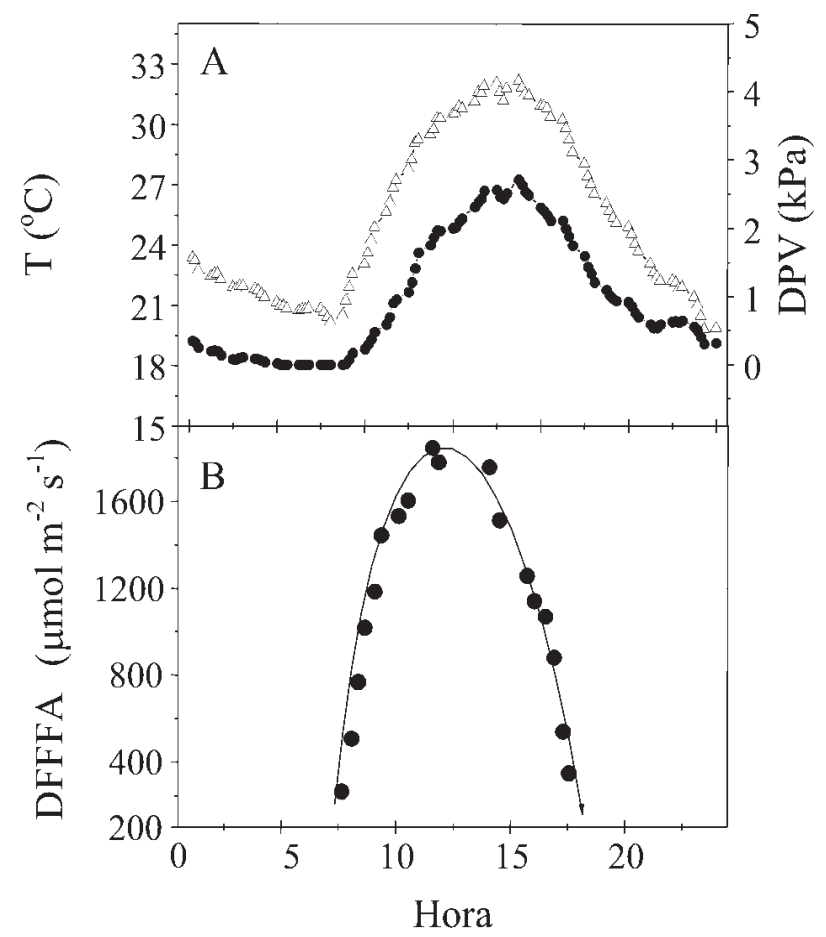

Figura 2. Variação diurna da temperatura do ar $(\mathrm{T}, \triangle)$ e do deficit de pressão de vapor (DPV, ๑) (A) e densidade de fluxo de fótons fotossinteticamente ativos (DFFFA) (B), no dia de medida de trocas gasosas e fluorescência da clorofila.
(McElrone et al., 2003; Alves et al., 2004) diminui o fluxo de água pelo pecíolo, inibindo parcialmente a capacidade de reidratação noturna das folhas. Por sua vez, durante o dia, o fechamento parcial dos estômatos, mais pronunciado nas plantas com CVC, não foi suficiente para prevenir a maior queda de $\Psi$ em relação às plantas sadias e, conseqüentemente, maior queda nas taxas de assimilação de $\mathrm{CO}_{2}$ e de transpiração (Figuras 3 e 4).

Houve queda acentuada no fluxo de seiva da planta inteira e da transpiração em folhas individuais de plantas infectadas pela $X$. fastidiosa. No entanto, em ambos os tratamentos, os padrões de respostas do fluxo de seiva, na planta inteira, e de transpiração, no curso de um dia, foram aparentemente diferentes (Figuras 1 e 4). Se, por um lado, há uma relação positiva entre o fluxo de seiva e o DPV, no curso do dia (Figuras 1 e 4), por outro, a relação positiva entre transpiração e DPV ocorre somente nas primeiras horas da manhã, atingindo um valor máximo entre 9 e 10h. Depois deste horário, a taxa de transpiração diminui rapidamente, até o final da tarde (Figuras 2 e 4), indicando que, depois das 10h, o DPV

Hora

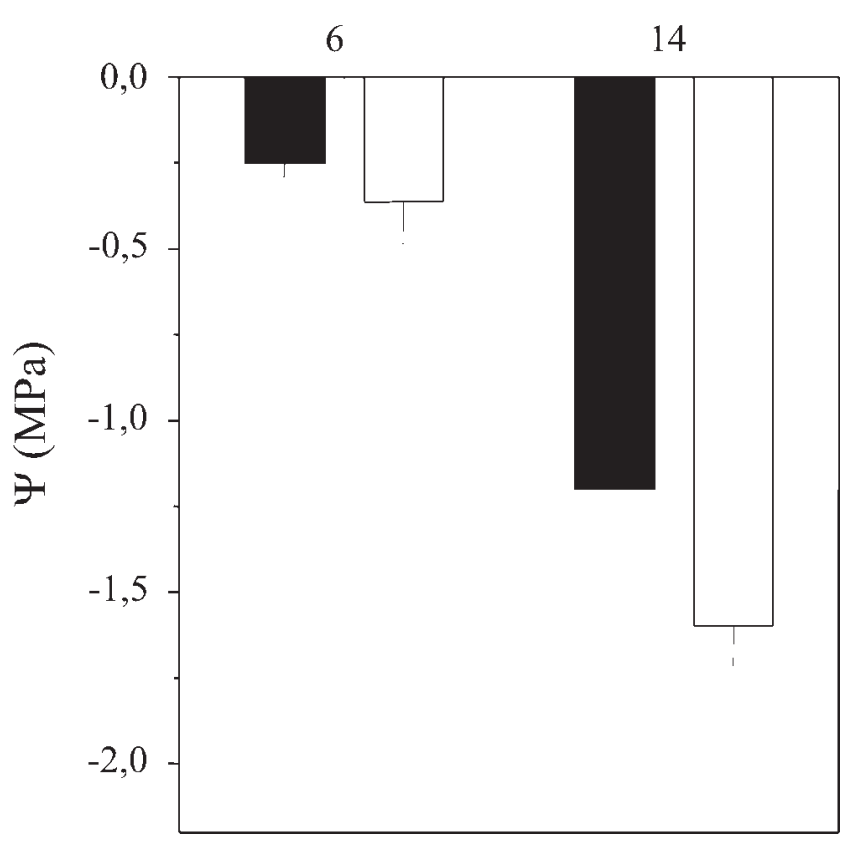

Figura 3. Potencial da água em folhas $(\Psi)$ de laranjeiras 'Natal' sadia ( $\square$ ) e com clorose variegada dos citros $(\square)$, medido às 6 e 14h. Barras representam os valores médios de quatro repetições, e as linhas verticais indicam os respectivos desvios-padrões. 
passa a exercer forte influência no mecanismo de abertura estomática.

Os valores máximos de transpiração, nas laranjeiras sadias e com CVC, foram $3,2 \mathrm{mmol} \mathrm{m}^{-2} \mathrm{~s}^{-1}$ e $2,5 \mathrm{mmol} \mathrm{m}^{-2} \mathrm{~s}^{-1}$, respectivamente, enquanto os valores médios máximos dos fluxos de seiva, calculados em unidades equivalentes, foram de $1,3 \mathrm{mmol} \mathrm{m}^{-2} \mathrm{~s}^{-1} \mathrm{e}$ $0,9 \mathrm{mmol} \mathrm{m}^{-2} \mathrm{~s}^{-1}$, respectivamente. A diferença entre os

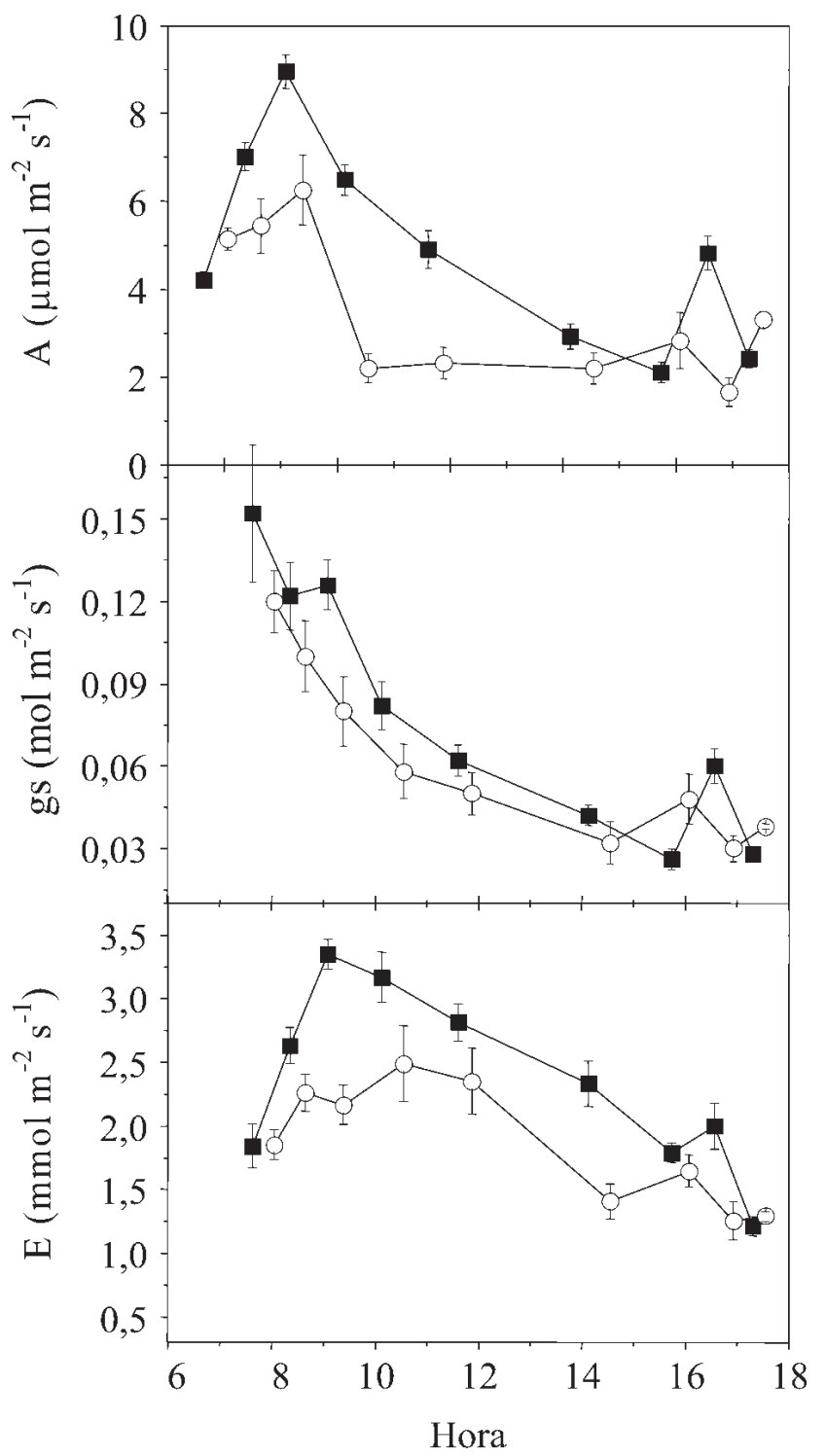

Figura 4. Variação diurna da taxa de assimilação líquida de $\mathrm{CO}_{2}$ (A), condutância estomática (gs) e taxa de transpiração (E) em folhas de laranjeira 'Natal' sadias ( $\square$ ) e com clorose variegada dos citros (O). Pontos representam as médias de cinco repetições, e as linhas verticais indicam os respectivos desvios-padrões. valores de fluxo de seiva e de transpiração está relacionada com o método de medida. Enquanto a transpiração foi medida de forma pontual, em folhas jovens e totalmente expandidas, expostas diretamente à radiação solar, o fluxo de seiva representa a média de todas as folhas da copa. Folhas diretamente expostas à radiação solar apresentam maior temperatura e, portanto, maior diferença de pressão de vapor entre folha e ar (Angelocci et al., 2004), proporcionando elevação na transpiração.

Com aumentos ainda maiores em DFFFA e de temperatura do ar e DPV, pode ocorrer defasagem entre a transpiração e a reposição da água por meio dos vasos do xilema, no pecíolo foliar, causando queda no conteúdo relativo de água e fechamento parcial dos estômatos nos períodos mais quentes do dia. Na copa das plantas, há distribuição de folhas com diferentes idades e intensidades de sombreamento, sendo as folhas internas sombreadas e mais velhas que as folhas da periferia. Esse arranjo proporciona queda na transpiração, ocasionada tanto pelo sombreamento quanto pela idade das folhas (Angelocci et al., 2004). Angelocci et al. (2004) observaram aumento da condutância estomática e da transiração, em função da DFFFA até cerca de $500 \mu \mathrm{mol} \mathrm{m}^{-2} \mathrm{~s}^{-1}$.

O fluxo de radiação das camadas mais profundas da copa decresce exponencialmente, causando diminuição da temperatura (Angelocci et al., 2004) e da transpiração das folhas mais internas. Valores máximos de condutância estomática foram observados entre 25 e $30^{\circ} \mathrm{C}$ (Medina et al., 1999; Ribeiro et al., 2004). Assim, esse arranjo das folhas deve ser a principal causa da menor taxa média de transpiração, estimada pelo fluxo de seiva, uma vez que, em todos os horários ou ângulos de inclinação solar, há folhas de diversas idades expostas totalmente à luz e outras totalmente sombreadas.

Nas laranjeiras infectadas pela $X$. fastidiosa, ocorreu queda de 43, 28 e 33\% na assimilação de $\mathrm{CO}_{2}$, condutância estomática e transpiração, respectivamente. Maior redução de assimilação de $\mathrm{CO}_{2}$ em relação à transpiração também foi verificada por Habermann et al. (2003a) e Ribeiro et al. (2003a, 2004). Em geral, uma mesma redução de condutância causa maior redução na transpiração do que na assimilação de $\mathrm{CO}_{2}$, devido às resistências envolvidas (Khairi \& Hall, 1976; Nobel, 1999). Assim, como o decréscimo da assimilação de $\mathrm{CO}_{2}$ nas plantas com CVC foi maior do que o decréscimo na transpiração, somente o menor valor de condutância 
estomática não explicaria totalmente o decréscimo na assimilação de $\mathrm{CO}_{2}$ das plantas infectadas. De fato, Ribeiro et al. (2003a, 2003b, 2004) e Habermann et al. (2003a) observaram que, além da queda da condutância estomática, fatores relacionados com reações bioquímicas e fotoquímicas também afetam a taxa de assimilação de $\mathrm{CO}_{2}$ em laranjeiras infectadas.

Em ambos os tratamentos, $\Phi_{\text {máxima }}$ decresceu de um valor ao redor de 0,82 , ao amanhecer, até valores próximos de 0,75 , em folhas sadias, e 0,69 , em folhas doentes, ao redor das $18 \mathrm{~h}$ (Figura 5 ). O decréscimo em $\Phi_{\text {máxima }}$ pode ser causado por baixa taxa de extinção da fluorescência ou devido a danos nos centros de reações do fotossistema II, ambos causando redução da eficiência quântica máxima (Baker \& Rosenqvist, 2004). O decréscimo de $\Phi_{\text {máxima, }}$ em plantas com CVC, indicou possíveis processos de fotoinibição, uma vez que havia excesso de energia, devido à menor taxa de fixação de $\mathrm{CO}_{2}$.

$\Phi_{\text {efetiva }}$ mostra a proporção da energia absorvida que é efetivamente utilizada nos processos fotoquímicos. Sob condições de laboratório, há relação linear entre essa variável e a fixação de $\mathrm{CO}_{2}$ (Genty et al., 1989). Em ambos os tratamentos, $\Phi_{\text {efetiva }}$ decresceu de acordo com o aumento de DFFFA, indicando que sob alta

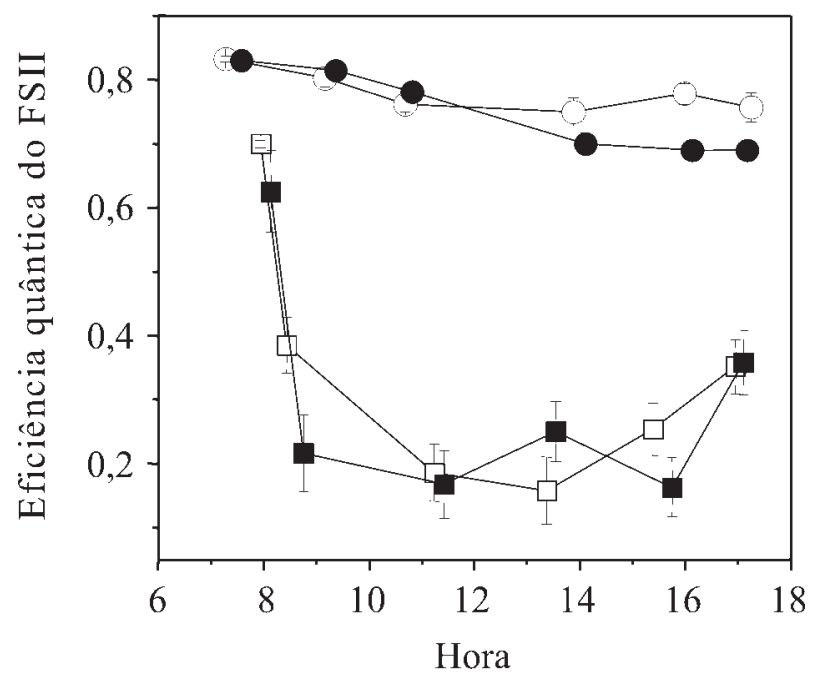

Figura 5. Variação diurna da eficiência quântica máxima (círculo) e efetiva (quadrado) em folhas de laranjeira 'Natal' sadias (símbolos vazios) e com clorose variegada dos citros (símbolos cheios). Pontos representam as médias de cinco repetições, e as linhas verticais indicam os respectivos desvios-padrões.
DFFFA, menor proporção dos elétrons é utilizada diretamente nas reações fotoquímicas e de redução do $\mathrm{CO}_{2}$. Ribeiro et al. (2003b) observaram redução de $\Phi_{\text {efetiva }}$ em valores de DFFFA acima de $150 \mu \mathrm{mol} \mathrm{m}^{-2} \mathrm{~s}^{-1}$, sendo tal resposta acompanhada pelo aumento da extinção não-fotoquímica da fluorescência. Mesmo com o decréscimo de $\Phi_{\text {efetiva }}$ sob alta radiação, a taxa aparente de transporte de elétrons, em laranjeira com CVC, é semelhante à das plantas sadias (Ribeiro et al., 2003b). A redução de $\Phi_{\text {efetiva }}$ pode representar um mecanismo de rápida adaptação do aparato fotossintético à alta radiação (Baker \& Rosenqvist, 2004). No entanto, apesar de a assimilação de $\mathrm{CO}_{2}$ ter sido menor nas plantas com CVC (Figura 4), a dinâmica diurna de $\Phi_{\text {efetiva }}$ foi semelhante $(\mathrm{p}<0,05)$ em ambos os tratamentos. Ribeiro et al. (2003a, 2004) observaram valores semelhantes de $\Phi_{\text {efetiva }}$ em plantas sadias e com CVC, mas também verificaram aumento da utilização dos elétrons gerados pela fotoquímica em rotas alternativas. De fato, Habermann et al. (2003a) observaram que a fotorrespiração aumenta significativamente em laranjeiras com CVC, e este processo funciona como uma rota alternativa, visto que há aumento da atividade de oxigenação da rubisco (ribulose bisfosfato carboxilase/oxigenase) com consumo de ATP e de redutores (Laisk et al., 1998). Quando suprimida a fotorrespiração sob alta concentração de $\mathrm{CO}_{2}$, Ribeiro et al. (2003a, 2003b) constataram maiores valores de $\Phi_{\text {efetiva }}$ em plantas sadias sob baixa radiação.

\section{Conclusões}

1. A clorose variegada dos citros causa queda da transpiração, do fluxo de seiva, e da condutância estomática, em virtude da colonização dos vasos do xilema pela Xylella fastidiosa.

2. Laranjeiras com clorose variegada dos citros apresentam menor taxa de assimilação de $\mathrm{CO}_{2}$, ocasionada pela menor condutância estomática e possíveis comprometimentos bioquímicos.

\section{Agradecimentos}

À Fapesp, pelo apoio financeiro e concessão de bolsa a Rafael Vasconcelos Ribeiro; ao CNPq, pela concessão de bolsas a Eduardo Caruso Machado e Camilo Lázaro Medina; aos diretores e funcionários da Estação Experimental de Citricultura de Bebedouro. 


\section{Referências}

ALVES, E.; MARUCCI, C.R.; LOPES, J.R.S.; LEITE, B. Leaf symptoms on plum, coffee and citrus and the relationship with the extent of xylem vessels colonized by Xylella fastidiosa. Journal of Phytopathology, v.152, p.291-297, 2004.

AMORIM, L.; BERGAMIN FILHO, A.; PALAZZO, D.A.; BASSANEZI, R.B.; GODOY, C.V.; TORRES, G.A.M. Clorose variegada dos citros: uma escala diagramática para avaliação da severidade da doença. Fitopatologia Brasileira, v.18, p.174-180, 1993.

ANGELOCCI, L.R.; MARIN, F.R.; OLIVEIRA, R.F.; RIGHI, E.Z. Transpiration, leaf diffusive conductance, and atmospheric water demand relationship in an irrigated acid lime orchard. Brazilian Journal of Plant Physiology, v.16, p.53-64, 2004.

BAKER, N.R.; ROSENQVIST, E. Applications of chlorophyll fluorescence can improve crop production strategies: an examination of future possibilities. Journal of Experimental Botany, v.55, p.1607-1621, 2004.

BILGER, W.; SCHREIBER, U.; BOCK, M. Determination of the quantum efficiency of photosystem II and of non-photochemical quenching of chlorophyll fluorescence in the field. Oecologia, v.102, p.425-432, 1995.

GENTY, B.; BRIANTAIS, J.M.; BAKER, N.R. The relationship between the quantum yield of photosynthetic electron transport and quenching of chlorophyll fluorescence. Biochimica et Biophysica Acta, v.990, p.87-92, 1989.

HABERMANN, G.; MACHADO, E.C.; RODRIGUES, J.D.; MEDINA, C.L. $\mathrm{CO}_{2}$ assimilation, photosynthetic light response curves, and water relations of 'Pêra' sweet orange plants infected with Xylella fastidiosa. Brazilian Journal of Plant Physiology, v.15, p.79-87, 2003a.

HABERMANN, G.; MACHADO, E.C.; RODRIGUES, J.D.; MEDINA, C.L. Gas exchange rates at different vapour pressure deficits and water relations of 'Pêra' sweet orange plants with citrus variegated chlorosis (CVC). Scientia Horticulturae, v.98, p.233245, 2003b.

KAUFMANN, M. Evaluation of the pressure chamber method for measurement of water stress in citrus. Proceedings of the American Society for Horticultural Science, v.93, p.186-198, 1968.

KHAIRI, M.M.A.; HALL, A.E. Temperature and humidity effects on net photosynthesis and transpiration of citrus. Physiologia Plantarum, v.36, p.29-34, 1976.

LAISK, A.; RASULOV, B.H.; LORETO, F. Thermoinhibition of photosynthesis as analyzed by gas exchange and chlorophyll fluorescence. Russian Journal of Plant Physiology, v.45, p.412421, 1998.
MACHADO, E.C.; QUAGGIO, J.A.; LAGÔA, A.M.M.A.; TICELLI, M.; FURLANI, P.R. Trocas gasosas e relações hídricas em laranjeira com clorose variegada dos citros. Brazilian Journal of Plant Physiology, v.6, p.53-57, 1994.

McELRONE, A.J.; SHERALD, J.L.; FORSETH, I.N. Interactive effects of water stress and xylem-limited bacterial infection on the water relations of a host vine. Journal of Experimental Botany, v.54, p.419-430, 2003.

MEDINA, C.L.; MACHADO, E.C.; GOMES, M.M.A. Condutância estomática, transpiração e fotossíntese em laranjeira 'Valência' submetida ao estresse hídrico. Brazilian Journal of Plant Physiology, v.11, p.29-34, 1999.

NOBEL, P.S. Physicochemical and environmental plant physiology. New York: Academic Press, 1999. 474p.

NUNES, W.M.C.; MEDINA, C.L.; MACHADO, M.A.; MACHADO, E.C.; CORAZZA-NUNES, M.J.; MULLER, G.W. Transmissão de Xylella fastidiosa para mudas de citros através da encostia de plantas-inóculo. Laranja, v.25, p.349-356, 2004.

POOLER, M.R.; HARTUNG, J.S. Specific PCR detection and identification of Xylella fastidiosa strains causing citrus variegated chlorosis. Current Microbiology, v.31, p.377-381, 1995.

PURCELL, A.H.; HOPKINS, D.L. Fastidious xylem-limited bacterial plant pathogens. Annual Review of Phytopathology, v.34, p.131-151, 1996.

RIBEIRO, R.V.; MACHADO, E.C.; OLIVEIRA, R.F. Early photosynthetic responses of sweet orange plants infected with Xylella fastidiosa. Physiological and Molecular Plant Pathology, v.62, p.167-173, 2003a.

RIBEIRO, R.V.; MACHADO, E.C.; OLIVEIRA, R.F. Growth- and leaf-temperature effects on photosynthesis of sweet orange seedlings infected with Xylella fastidiosa. Plant Pathology, v.53, p.334-340, 2004.

RIBEIRO, R.V.; MACHADO, E.C.; OLIVEIRA, R.F.; PIMENTEL, C. High temperature effects on the response of photosynthesis to light in sweet orange plants infected with Xylella fastidiosa. Brazilian Journal of Plant Physiology, v.15, p.89-97, 2003b.

SAKURATANI, T. A heat balance method for measuring water flux in the stem of intact plants. Journal of Agricultural Meteorology, v.37, p.9-17, 1981.

STEINBERG, S.; VAN BAVEL, C.H.M.; McFARLAND, M.J. A gauge to measure mass flow rate of sap in stems and trunks of woody plants. Journal of the American Society for Horticultural Science, v.114, p.466-472, 1989.

TREJO-CHANDIA, J.E.; ANGELOCCI, L.R.; OLIVEIRA, R.F. Aplicação do método de balanço de calor na determinação da transpiração de mudas de limoeiro. Scientia Agricola, v.54, p.221231, 1997. 